\title{
Aging: physical difficulties and safety in cooking tasks
}

\author{
N. I Ibrahim ${ }^{\mathrm{a}, \mathrm{b}^{*}}$ and S. Davies ${ }^{\mathrm{b}}$ \\ ${ }^{a}$ School of Manufacturing Engineering, University of Malaysia Perlis (UniMAP), Perlis, Malaysia \\ ${ }^{\mathrm{b}}$ School of Art and Design, Coventry University, UK
}

\begin{abstract}
It is known that many older people have difficulties in performing daily living activities such as cooking. These are due to the demands of the tasks and the changes in functional capabilities of the older people. This study examines cooking tasks performed by the aged that includes preparing and cooking meals, and storing kitchen tools in the kitchen. The objectives are to investigate the cooking difficulties encounter by older people and the safety concerning cooking tasks. This study focuses on individuals of age 65 years and above who can cook for themselves and/or family. Data were collected through observation, interviews, questionnaires and role play methods. The findings revealed that the common problems were due to the awkward body position where subjects had to bend down to take things from lower shelves, taking/storing things on higher shelves and cleaning the cooker. Moreover, the safety concerns were the layout of work centres (storage, cooker and sink), the use of cooker and opening packaging. It can be concluded that cooking difficulties are caused by inappropriate kitchen design and the decline of functional capabilities in older people.
\end{abstract}

Keywords: older people, physical difficulties, safety, cooking

\section{Introduction}

The number of older people is growing rapidly around the world. Today, there are 750 million people aged 60 and over, and by the year 2050, it is predicted to be just over 2 billion [20]. According to the United Nations (2009), the oldest old (aged 80 years and over) are the fastest growing segment of the older population, estimated to reach 402 million by 2050.

Generally, people change as they grow older. Physically, older people experience changes in stature and posture. The bones are more brittle and they are liable to fracture and osteoporosis. Furthermore, the joints become stiffer especially at the lower spine, hips and knees. Arthritis is a common joint problem, which limits people's range of movement and mobility. It does not only limit the activities that an individual can do but also increase dependency on others.
Studies had shown that older adults often have difficulties in performing daily living activities such as bathing and preparing meals $[13,25]$. These difficulties are because of the inability of the older individual to meet the environmental and tasks demands. It influences their capability to function effectively, which is called as person-environment problem [8, $10,13]$. Modern kitchens are some examples of design activities which normally do not taking into consideration the ageing process of people in mind. Features such as an extra deep storage will cause difficulties to take and store things. Whereas, work surfaces with metal finish will produce glare and may lead to accidents.

Conversely, kitchen is where most serious accidents involving older people usually happened [29]. From statistics, accidents in the kitchen accounts about $9.7 \%$ of total home accidents in 2002 . In UK, the accidents that involves older adults (age 65 years and above) are about 2,063. This includes accidents that

\footnotetext{
* Corresponding author. Nurul Ikhmar Ibrahim, School of Manufacturing Engineering, Main Campus Pauh Putra, University of Malaysia Perlis
} (UniMAP), 02600 Arau, Perlis, Malaysia. E-mail: ikhmar@unimap.edu.my, Tel. no. +6049885086, Fax no. +6049885034 
caused by misuse of kitchen appliances (cooker, oven, food processor), cooking utensils (frying pan, saucepan, wok), and cutlery (knife, fork, plate). Accidents may as well cause by health conditions and body position while stretching, stooping and turning [16]. Types of accidents are usually falls/trips/slips, burns, scalds and gas poisoning. According to Gray (1966), falls are the most frequent kind of mishap for both fatal and non-fatal accidents, which may seriously handicap old people. This is because falls can cause hip fractures and is a major cause of morbidity and mortality [29].

This study looks into how the aged perform cooking tasks that are preparing and cooking meals, and storing kitchen tools in the kitchen. The objectives are to investigate the cooking difficulties encounter by the older people and the safety concerning cooking tasks.

\section{Methods}

Several qualitative methods were used to obtain data from the older population. There were consists of interviews, observations, questionnaires and role play. Study was done on older adults, age 65 years and above who can cook for themselves and/or family. Each result was compared to identify common pattern and correlation between them.

\subsection{Interview}

Interviews were done with two experts who had experienced working with elderly people. They were an Occupational Therapist who was also an expert in assistive technology, and a Psychologist; both were from Department of Health and Life Sciences, Coventry University. This interview was done to get an overview of the problems older people usually facing in cooking. Based on these interviews, observations framework was made as the next method.

\subsection{Observations and interviews}

For these particular methods, six subjects were recruited from a community-dwelling centre in Coventry. They consisted of four women and two men, with various impairments and age range of 70 to 91 years old $($ Mean $=78.83, \mathrm{SD}=1.05)$. Each subject was assigned a code for ease of reference. Two video cameras were used and observations were conducted at the location where subjects were recruited.
The study was focused from preparing food to cleaning cooking utensils. During observations, subjects were asked about the difficulties they might have while performing the tasks and any other problems they usually had while cooking. Videos from the observations were analysed and then recorded on the observation records.

\subsection{Questionnaires}

Twenty sets of questionnaire were mailed and distributed through an organisation. Responded rate was $40 \%(n=8)$. The questionnaire was divided into two sections - cooking activities and safety in kitchen environment, and background information. The first section was concerned on the physical difficulties of working in the kitchen, emotional factors in cooking, safety issues involved and attitude towards technology. While the second section, dealt with subjects' personal background and needs. Respondents also were asked to include a rough diagram of their kitchen layout. Results then were coded based on frequent pattern of answers.

\subsection{Role play}

Role play is a method of acting out the roles of the intended users and performs specific activities in the real world. In this study, four role plays of older people were done. Each role play has had particular physical impairments that were believed to have an impact on cooking performance. They were:

Role Play 1: Older people that have arthritis on all finger joints, vision impairment and ankle injury. Role Play 2: Older people that have arthritis on all finger joints, reduced dexterity on both hands and mobility impairment.

Role Play 3: Older people that have back pain, wrist pain on right hand and lack of balance.

Role Play 4: Older people that have shoulder pain (right shoulder), reduced dexterity on both hands and macular degeneration.

Role plays were done in a large kitchen, having an Llayout. The meal cooked consists of three dishes; rice, seafood and vegetable. Each session lasted for about an hour. The controlled variables were tools and appliances used, kitchen layout and types of meal cooked. Each problem from each role-play was recognised and noted in the role play diary. It was further analysed by using task analysis method. Prob- 
lems that were recurrent among all role plays were then categorised and compared to the results obtained from questionnaire and observations.

\section{Results and discussion}

\subsection{Interactions in the work centres (from observa- tions)}

Subjects' interactions in the kitchen were based on types of meal they cooked. This determined the cooking tasks, tools and appliances used and the way subjects interacted within the work centres. Their cooking performance was affected by their capabilities and environmental demands. From task analysis, common tasks/actions and the objects involved in the kitchen are listed in Table 1.

The verb describes what the subject is doing and the object describes the component(s) of the environment involved in the subject's action [13]. In doing these tasks, common postures adopted were standing, stooping and bending (Figure 1). This analysis was furthered analysed to define cooking difficulties amongst subjects.

\subsection{Difficulties in cooking}

Results collected were compared to identify correlation of cooking difficulties particularly on physical aspect (Table 2). Then, these difficulties along with other data were classified according to subjects' abilities and environmental demands (kitchen design).

\subsubsection{Motor limitations}

This category was related to movement limitations that involve gross motor movement, fine motor movement or balance [28]. From Table 2, it was found that cooking tasks require a lot of physical demands and the common problems include bending, lifting and carrying, reaching, opening packages and fatigue. These are mostly consistent with studies done by Czaja et al. (1993) and Rogers et al. (1998). For this particular study, the issues associated were getting food in and out of the oven or lower storage, taking and/or storing things on higher shelves and having to stand for periods of time (for cooking and washing up tasks).

One female subject had had arthritis in the fingers and feet for more than six years and she stated that she could not cook certain food because it was hard and painful for her to cook it. Her main problems were cutting, lifting and carrying utensils, and opening packages. Rogers et al. (1998) mentioned in their study that arthritis in the hand contribute to fine motor movement problems which include opening a food bag or carton. On the other hand, a 91 year old male subject easily feels fatigue and could not lift and carrying heavy objects. He had mobility problem and often took breaks while cooking.

Besides that, subjects had complained about the effort needed in cleaning cooking appliances such as cooker and oven. The task was considered uncomfortable, difficult and requires a lot of time.

Overall, the demands in cooking tasks prove to be problematic for older people especially in physical aspects. This is because the older people experience a gradual decrease in strength as well as range of motion and dexterity. In fact, maintaining a balance or particular postural orientation for extended periods declines with age $[2,10]$.

\subsubsection{Inappropriate kitchen design.}

Major problem in the kitchen would be the arrangement and position of work centres and kitchen appliances. The kitchen in the community-dwelling centre was small and had a fixed L-layout. The worktops, hood and cooker were low. Fridges and freezers were placed below the worktops. Below the worktops was also storage for other things such as cleaning equipment and a trash bin. Subjects were required to bend very low to reach for food and other things (Figure 1a). Awkward posture was also adopted by subjects while cooking due to the low worktops. Being a tall woman and having a back pain, a female subject (stature $1825 \mathrm{~mm}$ ) complained about how the designer didn't consider about tall user in the kitchen and how for her having to bend very low every time she wants to prepare meals. Next, in role play, the kitchen had a deep lower storage that required more bending in reaching for tools and food.

Previous studies stressed on the design and location of the storage [10, 17-18, 22-23, 29]. Storage can be too high, too deep or awkward to reach particularly for reaching cooking tools such as pots. Kirvesoja, Vayrynen and Haikio (2000) found that elderly people had difficulties with top shelf on upper cupboard and shelf on lower cupboard. They suggested that kitchen shelves should have as much adjustment as possible for easy access [23]. This was further recommended by Clark et. al (1990) and Czaja et al. (1993) to provide a shallow storage at lower levels, or provide with pull-down shelves or adjustable shelves that can operated automatically. 

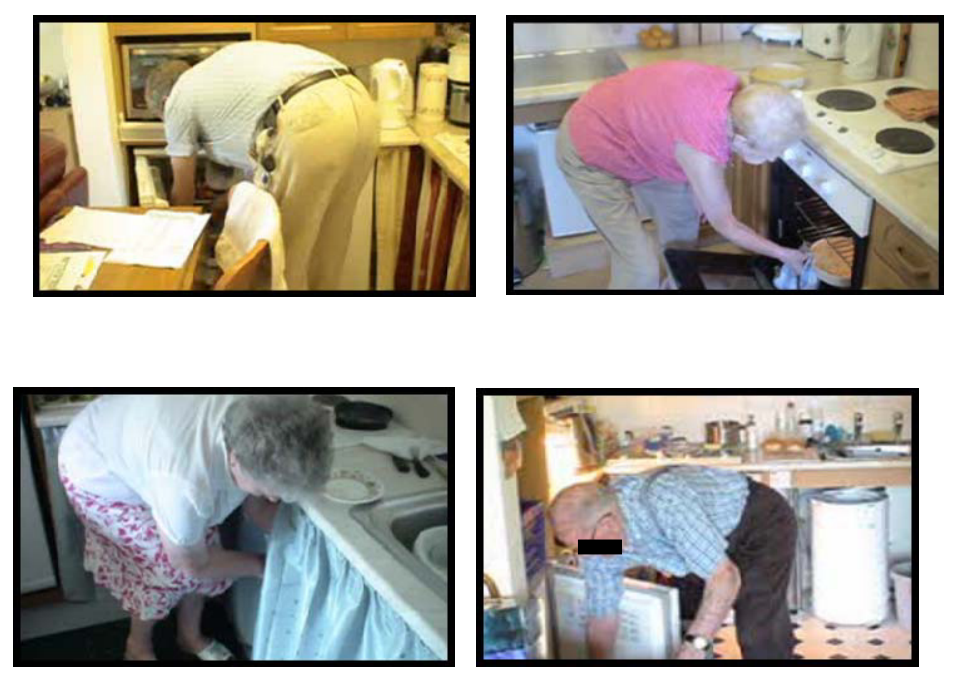

(a) Bending
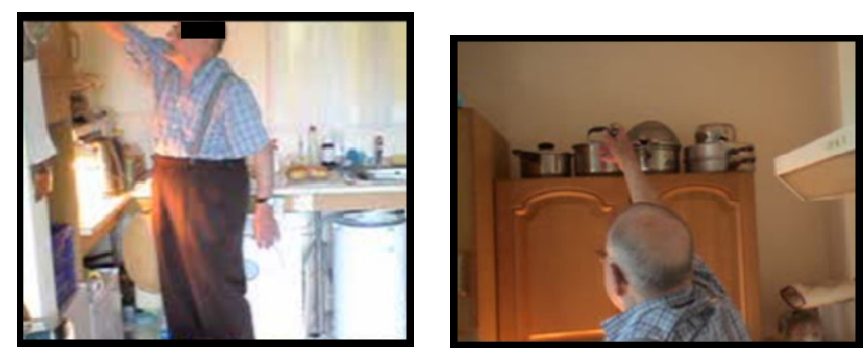

(b) Reaching

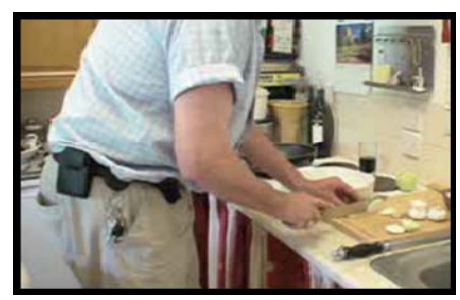

(c) Stooping

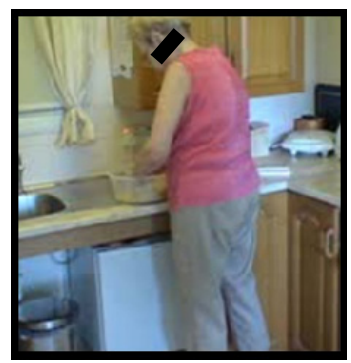

(d) Standing

Figure. 1: Postures adopted while cooking - Most storages and kitchen appliances were underneath the low worktop. Therefore, subjects had to bend very low to take things/food and throwing rubbish. Other postures include reaching, stooping and standing. 
Table 1

Common tasks/actions in cooking

\begin{tabular}{ll}
\hline & Environment (object) \\
\hline Actions (verb) & Packages/food \\
Mixing/stirring & Food \\
Opening/closing & Drawer/cupboard/oven door \\
Turning on/off & Device (switches) \\
Rinsing & Cooking tools \\
Removing/throwing & Trash \\
Cleaning/washing & Cooking tools/dinnerware \\
Lifting/carrying & Cooking tools/packages \\
Reaching & Cooking tools/food \\
Grasping & Cooking tools/packages \\
Pouring & Water/food \\
Twisting/rotating & Controls/packages \\
Scoop/ladle & Food from pot/pan \\
Draw/pull out & Food from packages \\
\hline
\end{tabular}

Table 2

Physical difficulties in cooking

\begin{tabular}{lcccc}
\hline & Interview & Questionnaire & Observation & Role Play \\
\hline Bending/reaching & $\mathrm{x}$ & $\mathrm{x}$ & $\mathrm{x}$ & $\mathrm{x}$ \\
Stooping & & & $\mathrm{x}$ & $\mathrm{x}$ \\
Lifting/carrying & $\mathrm{x}$ & $\mathrm{x}$ & $\mathrm{x}^{1}$ & $\mathrm{x}$ \\
Opening packages & $\mathrm{x}$ & $\mathrm{x}^{1}$ & $\mathrm{x}$ & $\mathrm{x}$ \\
Cleaning cooking & $\mathrm{x}$ & & $\mathrm{x}$ \\
appliances & & & $\mathrm{x}$ & \\
Mobility & $\mathrm{x}$ & $\mathrm{x}$ & $\mathrm{x}$ \\
Cutting & & $\mathrm{x}$ & $\mathrm{x}$ \\
Stirring & & & $\mathrm{x}$ \\
Fatigue & & & & \\
\hline
\end{tabular}

${ }^{1}$ Difficulties experienced by arthritic. Other subjects did not have these problems. 

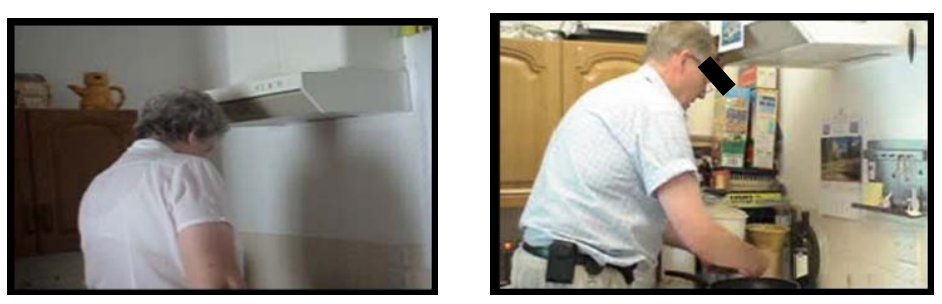

Figure 2: A low hood can cause head injury for tall subjects.
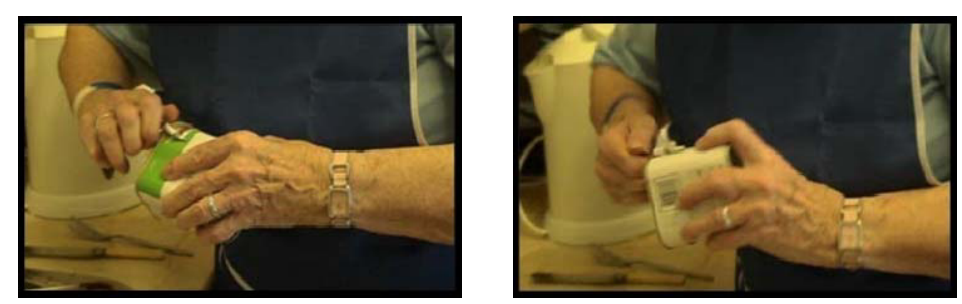

Figure 3: A female subject had to adopt an awkward posture to open a tin beef.

Furthermore, the layout of the kitchen affected subjects' cooking performance. Result from questionnaire showed that cooker and sink were placed separated across the room. These add to the unnecessary and exhaustive journeys in the kitchen that will lead to accidents. In a face-to-face interview, Dr. Gillian Ward from Coventry University said, "The more people have to move things around in the kitchen, obviously the more risk there is." (personal communication, May 12, 2009)

Therefore, the layout of the kitchen especially the nearness of the work centres must be given a priority. The storage must be easily accessible and each work centre must consider the extreme users.

\subsection{Safety.}

Older adults are liable to have accidents like instance falls, burns and scalds in the kitchen. Main causes are the age-related changes and the design of the kitchen environment. For example, reaching a pot on a higher shelf may result in the person to fall because of failing to balance himself/herself on a stool. As of the study, no subjects had fall in their kitchen except a female subject. Having arthritis in her feet, she had fall while cooking and both of her hands had burnt while trying to get up.
As mentioned in previous section, design of the kitchen can contribute to accidents or injuries. Improper position and location of the working centres namely the storage (e.g. fridge), cooker and sink may cause the elderly people to trip and fall. Dr. Gillian Ward said that a continuous worktop is very useful for older people so that they can slide things along without having to lift anything (personal communication, May 12, 2009).

Other safety concerns were the low hood, which can cause head injury while cooking (Figure 2), and the use of electric cooker. It was found that most subjects were quite anxious about using the cooker. It was because the cooker usually retains heat for awhile after turning off and sometimes they were not aware of this. As a result, the older people were exposed to burns and scalds.

In addition, opening tin cans was proved to be dangerous, as subjects may cut and get hurt. Particularly for key-operated and ring-pull tins require significant amount of strength and fiddly posture to open it (Figure 3). This can lead to packaging accidents as demonstrated by Department of Trade and Industry, UK, (1999) Duizer, Robertson and Han (2009) and Winder et al. (2008). 


\section{Conclusion}

Cooking is one of the routine living activities that demand certain amount of physical strength. This includes cutting, opening packages, lifting and carrying, and cleaning utensils. This study presents how cooking tasks affects the physical abilities of the older people. Moreover, the results show that design of kitchen which neglects the needs of older people make the cooking tasks more difficult and risky. In conclusion, cooking difficulties are caused by inappropriate kitchen design and the decline of functional capabilities in older people. It has not only reduced functional independence but also lost sense of fun and pleasure associated with cooking.

\section{Acknowledgement}

The authors would like to express appreciation to The ExtraCare Charitable Trust (Humber Court, Coventry), Arthritis Care Central England Region, and all the individuals that had given their kind cooperation in completing this research.

\section{References}

[1] Aiken, L. R. (1995). Aging: An Introduction to Gerontology. Thousand Oaks, California; London: Sage Publications, Inc.

[2] Bee, H. (1994). Lifespan Development. New York: HarperCollins College Publishers.

[3] Belson, W. A. (1981). The Design and Understanding of Survey Questions. Aldershot, Hants: Gower Publishing Co. Ltd.

[4] Berenbaum, R. L. J. (1994). Cooking as a therapy with the confused elderly. Activities, Adaptation and Aging, 19 (1), 53 -59 .

[5] Berger, K. S. (2005) The developing person: Through the life span (6th ed.). New York: Worth Publishers.

[6] Carter, S. E., Campbell, E. M., Sanson-Fisher, R. W., Redman, S. and Gillespie, W. J. (1997). Environmental hazards in the homes of older people. Age and Ageing, 26, 195 - 202.

[7] Charles, N. and Bosman, E. A. (1992). Human Factors and aging. In Craik, F. I. M. and Salthouse, T. A. (Eds.), The handbook of aging and cognition (pp. 495-552). New Jersey: Lawrence Earlbaum Associates, Inc.

[8] Clark, M. C., Czaja, S. J., and Weber, R. A. (1990) .Older adults and daily living task profiles. Human Factors, 32 (5), $537-649$.

[9] Craik, F. I. M. and Bialystok, E. (2006). Planning and task management in older adults: Cooking breakfast. Memory \& Cognition, 34 (6), 1236 - 1249.

[10] Czaja, S. J., Weber, R. A. and Nair, S. N. (1993). A human factors analysis of ADL activities: A capability-demand approach. The Journal of Gerontology, 48 (Special Issue), 44 48.
[11]Department of Trade Industry (1999) Government Consumer Safety Research. Assessment of Broad Age-Related Issues for Package Opening. DTI, London.

[12]Duizer, L.M., Robertson, T., and Han, J. (2009) Requirements for packaging from an ageing consumer's perspective. Packaging Technology and Science, 22, 187-197.

[13]Faletti, Martin V. (1984). Human factors research and functional environments for the aged. In Altman, I., Lawton, M. P., and Wohlwill, J. F. (Eds.). Elderly people and the environment (pp. 191-237). New York: Plenum Press.

[14]Fisk, D., Rogers, W. A., Charness, N., Czaja, S. J. and Sharit, J. (2004). Designing for older adults: Principles and creative human factors approaches. Boca Raton, FL; London CRC Press.

[15]Foott, S., Lane, M., and Mara, J. (1975) Kitchen sense for disabled people of all ages. London: William Heinemann Medical Books.

[16] Gilhooly, M. and Lightbody, P. (1998). Home accidents amongst elderly people: A locality study in Scotland. no Paisley, Scotland: University of Paisley.

[17] Grandjean, E. (1973). Ergonomics of the home. London: Taylor and Francis Ltd.

[18] Gray, Barbara (1966). Home accidents among older people: Report of a research carried out in the Birmingham area. London: The Royal Society for the Prevention of Accidents

[19] Gresham, M. (1999). The heart of the home - but how are kitchens used. Journal of Dementia Care, 7 (2), 22 - 23.

[20]Help The Aged (2008). International Facts. Retrieved from http://www.helptheaged.org.uk/NR/rdonlyres/759CCFCC911F-4AFC-9D1F-6F9C82BD993E/0/international facts.pdf.

[21] HelpAge International (2009). Global Ageing Statistics. Retrieved from

http://www.helpage.org/Researchandpolicy/Stateoftheworldso lderpeople/Globalstatistics.

[22] Howie, P. M. (1968). A pilot study of disabled housewives in their kitchens. London: Disabled Living Foundation.

[23] Kiversoja, H., Vayrynen, S. and Haikio, A. (2000). Three evaluations of task-surface heights in elderly people's homes. Applied Ergonomics, 31, $109-119$.

[24]Lawton, P. (1990). Aging and performance of home tasks. Human Factors, 32 (5), 527 - 536.

[25] National Center for Health Statistic, Dawson, D., Hendershot, G. and Fulton, J. (1987). Aging in the eighties: Functional limitations of individuals age 65 years and over. Advance Data From Vital and Health Statistics. No. 133. (DHHS Pub. No. PHS 87-1 250).

[26] Pearson, V. I. (2000). Assessment of function in older adults. In Kane, R. L., Kane, R. A. and Eells, w. a. o. M. (Eds). Assessing older persons: Measures, meaning and practical applications (pp. 17-48). Oxford [England]; New York: Oxford University Press.

[27] Raven, S. R. (2006). Guidelines for designing kitchen appliances for the elderly. Unpublished Master thesis. Auburn University, Alabama.

[28] Rogers, W. A., Meyer, B., Walker, N. and Fisk, A. D. (1998). Functional limitations to daily living task in the aged: A focus group analysis. Human Factors, 40 (1), 111 - 125.

[29] RoSPA. (2009). Home and leisure accident surveillance system - 2002 annual report. Retrieved April 15, 2009, from http://www.hassandlass.org.uk/query/reports.htm.

[30] United Nations Department of Economic and Social Affairs, Population Division. (2009). World population prospects: The 2006 revision. Retrieved June 13, 2009, from http://www.un.org/esa/population/publications/wpp2006/WPP 2006_Highlights_rev.pdf. 
[31] Winder, B., Ridgway, K., Nelson, A. and Baldwin, J. (2002).

Food and drink packaging: Who is complaining and who should be complaining. Applied Ergonomics, 33, 433-438. 